\title{
Improving Greenhouse Heating in Portugal
}

J.F. Meneses ${ }^{\mathrm{a}}$

Dept. Engenharia Rural, CEER

Instituto Superior de Agronomia, UTL

Tapada da Ajuda, 1349-017 Lisboa

Portugal

\author{
F.J. Baptista \\ Universidade de Évora/ICAM \\ Departamento de Engenharia Rural \\ Núcleo da Mitra \\ Apartado 94, 7002-554 Évora \\ Portugal
}

Keywords: energy saving, greenhouses, heating systems

\begin{abstract}
Although several new solutions for greenhouse heating and environmental control are being investigated all over the world; to reduce energy consumption and environmental impacts, to increase the efficiency of energy use for plant production in protected cultivation or to take advantage of the new renewable energy sources, in Portugal the great majority of producers still rely on more conventional heating systems for an economical year round production of vegetables and flowers. The objective of this work is to review some guidelines to help the grower when choosing the best heating solutions for different crops and cultivation systems. First, the level of heating required is defined and the correspondent heating power is analysed. Secondly, the main heating systems are mentioned including their components, characteristics, effects on greenhouse climate, soil and plant temperature. Relative costs of equipment and energy consumption are analyzed and some examples of practical solutions are presented from vegetable and flower production growers. Finally, several strategies to reduce the energy required for greenhouse heating are given and studied, including greenhouse structures, covering materials, thermal screens, air temperature and humidity control.
\end{abstract}

\section{INTRODUCTION}

In Portugal many greenhouse growers of vegetables, flowers and some of pot plants do not use heating. They make the most of the external weather conditions to produce during the best periods of the year for their particular crops. So most greenhouses were built near the sea from the north near Porto, in the West region (in the centre) around Torres Vedras to the Algarve in the south at the Faro plain. Outside design air temperatures range from 0 to $6^{\circ} \mathrm{C}$ in most places in the continent but may rise up to $10^{\circ} \mathrm{C}$ in the Atlantic archipelagos of Madeira and the Azores. This system of production, which is typical in the south of Europe, was called mild-winter greenhouse production (Meneses and Monteiro, 1993) and relies in a minimum investment in greenhouses. Climate control is mainly based on natural ventilation but leads to temperature, humidity and disease control problems during part of the year (Meneses et al., 1994).

More recently some growers started thinking to improve their production system through a better greenhouse climate control, not only to extend the period of production for all year round but also to obtain vegetables and flowers out of season with higher yields and better quality for a more demanding Portuguese or European market.

This paper was written to review some aspects to help the grower when choosing the heating systems and their heating strategies for different crops and cultivation systems. We will consider the heating requirements, the characteristics of different heating systems, their effects on greenhouse climate, relative costs and finally discuss some options to reduce the energy required for greenhouse heating.

\section{HEATING REQUIREMENTS}

To be able to choose the appropriate heating system the grower has to decide

a jmeneses@isa.utl.pt 